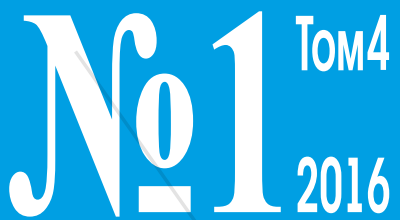

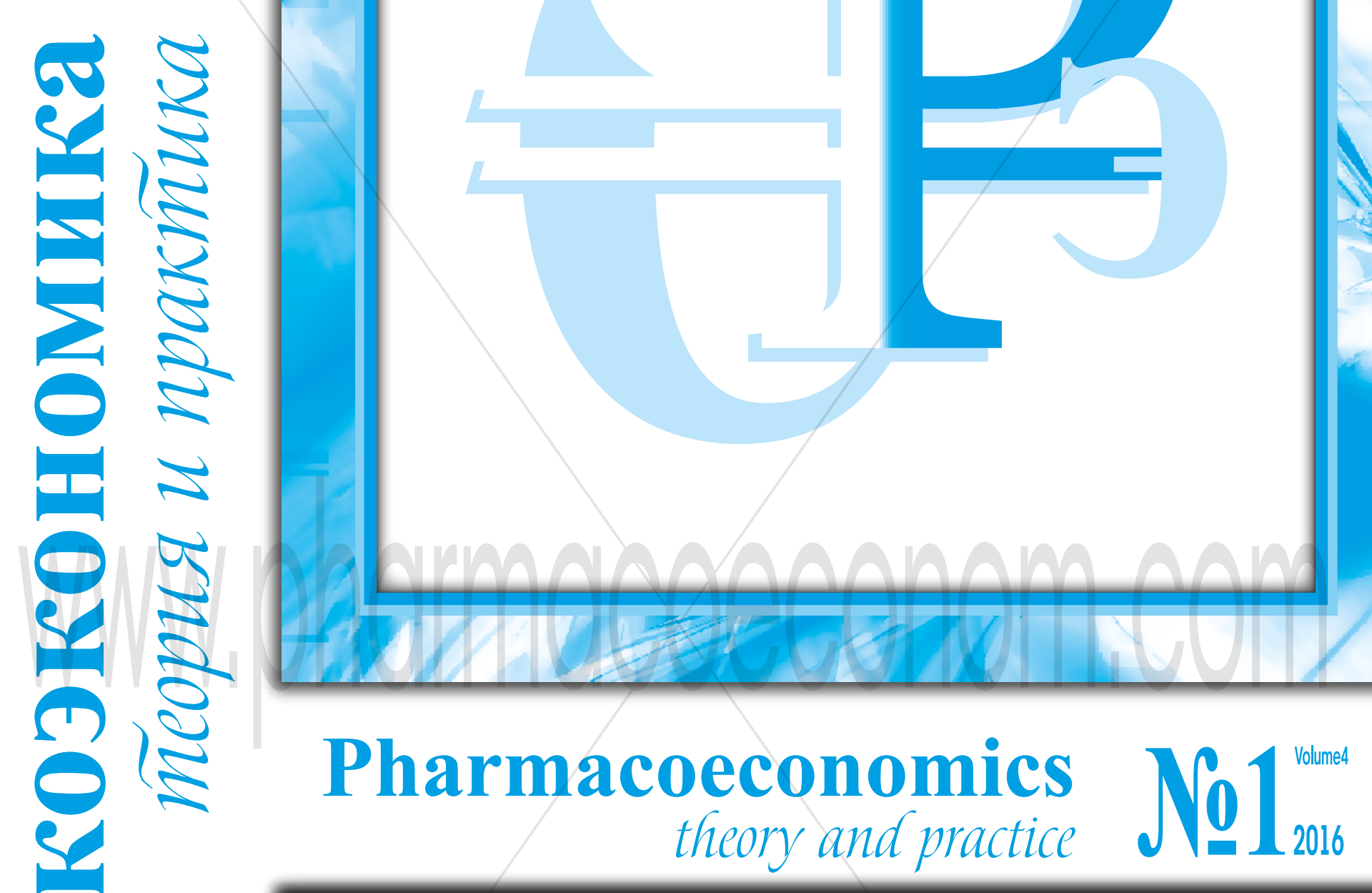

$\square$ МЕТОДОЛОГИЧЕСКИЕ ОСНОВЫ ФАРМАКОЭКОНОМИЧЕСКОГО МОДЕЛИРОВАНИЯ

$\square$ РЕЗУЛЬТАТЫ РОССИЙСКИХ ФАРМАКОЭКОНОМИЧЕСКИХ ИССЛЕДОВАНИЙ

口 МАТЕРИАЛЫ Х НАЦИОНАЛЬНОГО КОНГРЕССА С МЕЖДУНАРОДНЫМ УЧАСТИЕМ «РАЗВИТИЕ ФАРМАКОЭКОНОМИКИ И ФАРМАКОЭПИДЕМИОЛОГИИ В РОССИЙСКОЙ ФЕДЕРАЦИИ» 4-5 апреля 2016 г., г. Нижний Новгород 


\title{
ПОВЕДЕНИЕ ФАРМАЦЕВТИЧЕСКИХ РАБОТНИКОВ АНТИБИОТИКОВ ДЛЯ СИСТЕМНОГО ПРИМЕНЕНИЯ
} ПРИ

\author{
PHARMACISTS ACTIONS IN ANTIBIOTICS SALES
}

\author{
Якимова Ю.Н., Решетько О.В. \\ Yakimova Yu.N., Reshetko O.V.
}

\author{
ГБОУ ВПО Саратовский ГМУ им. В.И. Разумовского Минздрава России, г.Саратов \\ Saratov State Medical University named after V.I. Razumovsky, Saratov
}

\begin{abstract}
Ключевые слова: антибактериальные препараты, антибиотики, фрармацевтические работники, фрармацевтическое консультирование, отпуск лекарственных препаратов.
\end{abstract}

Введение: самолечение антибиотиками является одним из главных факторов необоснованного применения антимикробных препаратов. Жители России самостоятельно решаются принимать антибиотики в $21 \%$ случаев заболеваний ОРВИ, ОРЗ и гриппом, что значительно повышает роль фармацевтического работника при отпуске антибиотиков.

Цель исследования: выявить особенности фармацевтического консультирования посетителей аптек при покупке антибиотиков для системного применения.

Материалы и методы: было проведено фрармакоэпидемиологическое исследование, основанное на анкетировании 302 фармацевтических работников первого стола с использованием специально разработанной анкеты. Данные были обработаны с помощью Microsoft Excel с применением методов непараметрической статистики.

Результаты: подавляющее большинство респондентов - женщины $(96,7 \%)$ со средним фрармацевтическим образованием $(77,8 \%)$. Средний

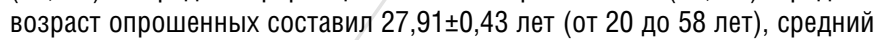
стаж работы $-6,72 \pm 0,40$ лет (от 0,5 до 36 лет). Почти все специалисты $(97,0 \%)$ отмечают, что ежедневно сталкиваются с отпуском антибиотиков (в том числе $56,3 \%$ - несколько раз в день). $13,9 \%$ респондентов указали, что пациенты всегда обращаются в аптеку без рецепта для покупки антибиотика, 76,2\% специалистов часто сталкиваются с данной ситуацией. При этом всегда требуют предъявить рецепт врача $45,7 \%$ опрошенных. 5,3\% специалистов никогда не спрашивают у покупателей рецепт на антибиотик. Почти все опрошенные $(99,7 \%)$ отметили, что пациенты обращаются к ним за консультацией по поводу выбора и особенностей приема антибиотика. 25,8\% опрошенных всегда консультируют пациентов при покупке антибиотика. При этом специалисты чаще всего обращают внимание пациента на режим приема препарата $(78,2 \%)$, а также на показания $(74,2 \%)$ и противопоказания $(70,5 \%)$ для его применения. По мнению опрошенных, при выборе антибиотика наибольшее значение (по шкале от 1 до 5) имеют фармакотерапевтические характеристики препа- рата: эффективность $(4,66 \pm 0,03)$ и безопасность $(4,26 \pm 0,05)$. Вторыми по значимости выступают экономические характеристики: доступность цены препарата для пациента $(3,78 \pm 0,05)$ и доход от реализации препарата $(3,05 \pm 0,16)$. Частота назначений антибиотиков врачами и частоту рекомендаций антибиотиков в аптеке была оценена респондентами по шкале от 0 до 3. По их мнению, чаще всего назначают/рекомендуют препараты пенициллинового $(2,02 \pm 0,0 / 1,29 \pm 0,07)$ и цесралоспоринового ряда $(2,51 \pm 0,04 / 1,40 \pm 0,06)$, а также макролиды $(2,40 \pm 0,04 / 1,50 \pm 0,06)$. Среди наиболее часто назначаемых/рекомендуемых средств были названы азитромицин $(73,5 \% / 46,0 \%)$, амоксициллин+клавулановая кислота $(59,6 \% / 38,7 \%)$, амоксициллин (45,4\%/24,5\%). 22,9\% опрошенных указали, что не рекомендуют антибиотики посетителям аптеки. 42,1\% опрошенных отмечают, что знакомы с ассортиментом и особенностями большей части антибиотиков. 36,4\% специалистов знакомы с ассортиментом наиболее популярных препаратов и их основными особенностями. Лишь 15,2\% респондентов указывают, что в полном объеме знакомы с ассортиментом и особенностями антибиотиков. $63,6 \%$ респондентов утверждают, что назначение антибиотиков должно осуществляться только врачом. Тем не менее, на практике своего решения строго придерживается лишь 29,7\% специалистов данной группы. 25,5\% опрошенных считают, что фрармацевт может рекомендовать антибиотики в некоторых очевидных случаях (типичное течение заболевания, наличие у пациента хронических заболеваний и опыта приема препарата и пр.). 10,9\% специалистов уверены, что консультации фрармацевта при выборе антибиотика достаточно (при этом 45,5\% из них знакомы с основными особенностями лишь наиболее популярных препаратов данной группы).

Заключение: фрармацевтические работники постоянно осуществляют отпуск антибиотиков и консультирование пациентов по вопросам их применения, что требует от специалистов высокого уровня квалисикации. По результатам самооценки специалисты не обладают обширными знаниями об особенностях антибиотиков. Некоторые фармацевтические работники считают возможным самостоятельно рекомендовать и отпускать препараты без назначения врача. Результаты исследования подтверждают необходимость совершенствования профессиональных знаний фармацевтических работников по вопросам применения антибиотиков. 